\title{
IMPLEMENTASI KEBIJAKAN PENGADAAN PEGAWAI PEMERINTAH DENGAN PERJANJIAN KERJA (PPPK) DI LINGKUNGAN PEMERINTAH KABUPATEN BANDUNG
}

\author{
Ghina Hanamunika ${ }^{1}$, Deasy Silvya Sari ${ }^{2}$, Ratna Meisa Dai ${ }^{3}$ \\ Program Pasca Sarjana Kebijakan Publik, Fakultas Ilmu Sosial dan Ilmu Politik \\ Universitas Padjadjaran \\ hanamunika@gmail.com
}

\begin{abstract}
ABSTRAK
Artikel ini bertujuan menganalisis mengenai Implementasi Kebijakan Pengadaan Pegawai Pemerintah dengan Perjanjian Kerja (PPPK) di Lingkungan Pemerintah Kabupaten Bandung, menggunakan model implementasi kebijakan model teori David L.Weimer dan Aidan R.Vinning. Metode kualitatif penulis menemukan bahwa implementasi kebijakan Pengadaan PPPK di Lingkungan Pemerintah Kabupaten Bandung dilaksanakan melalui proses berikut (i) logika kebijakan, (ii) lingkungan tempat kebijakan, (iii) kemampuan implementor kebijakan. Kebijakan ini dibuat agar pegawai Non PNS atau disebut tenaga honorer baik dilingkungan pemerintah pusat dan daerah dapat beralih status mejadi bagian pegawai ASN yang disebut PPPK sehingga mereka mendapatkan hak dan kewajiban yang sama seperti pegawai lainya, selain itu kebijakan ini juga bertujuan untuk pengaturan pegawai yang bekerja di lingkungan pemerintahan, dan meningkatkan profesionalisme dalam kepegawaian.
\end{abstract}

Kata Kunci : PPPK, Pengadaan Pegawai, Implementasi Kebijakan

\begin{abstract}
This article aims to analyze the implementation of the Government Employee Procurement Policy with a Work Agreement (PPPK) in the Bandung Regency Government, using the policy implementation model of the theory of David L. Weimer and Aidan R.Vinning. The author's qualitative method found that the implementation of the Government Employee Procurement Policy PPPK in the Bandung Regency Government was carried out through the following processes (i) policy logic, (ii) the environment where the policy was, (iii) the ability of policy implementers. This policy was made so that non-PNS employees or called honorary staff both in the central and local government circles could switch their status to become part of ASN employees called PPPK so that they get the same rights and obligations as other employees, besides that this policy also aims to regulate employees who work. in government circles, and increase professionalism in staffing.
\end{abstract}

Keywords: PPPK, Employee Procurement, Policy Implementation 


\section{PENDAHULUAN}

PPPK merupakan unsur pegawai di Lingkungan Pemerintah Kabupaten Bandung yang resmi keberadaannya sama seperti halnya di lingkungan pemerintah daerah lainnya. Menurut (Kurniawan, 2020) bahwa upaya pemerintah kabupaten Aceh Utara untuk melaksanakan PP No.49 Tahun 2018 tentang PPPK dengan melakukan pengisian formasi yang kosong dengan merekrut pegawai yang bersumber dari pegawai PTT dan dinas pertanian yang ada di lingkungan tersebut,guna terpenuhi kebutuhan SDM, meskipun kenyataan anggaran daerah sangat terbatas.Konsep PPPK yang diberlakukan untuk alternatif pengisian formasi yang kosong mengacu kesetaraan ASN dalam hal ini Pegawai PPPK itu samahalnya dengan PNS hak dan kewajibanya, hanya perbedaanya terletak pada tunjangan di masa tua (faedlulloh, 2015) Perlindungan terhadap PPPK belum secara penuh diatur oleh pemerintah, hal ini disebabkan regulasi yang ada belum menjelaskan secara rinci mengenai perlindungan hukum, adanya ketidakadilan terhadap PPPK dengan PNS yg statusnya merupakan ASN namun terdapat perbedaan terhadap jaminan hari tua, selain itu PPPK yang sudah mengabdi lama di instansi tertentu tidak dinilai karena penerimaanya sama melalui jalur umum (Ayunintyas, 2017). Tantangan dalam penerapan PPPK di pemerintah daerah terletak pada kinerja, bahwa kinerja pegawai PPPK harus tenaga professional atau mempunyai keahlian sesuai yang tertuang dalam aturan, hal ini yang harus diluruskan dalam implementasi kebijakan PPPK bahwa PPPK bukan pengganti nama tenaga honor namun tenaga honor yang berkualitas dan berkompeten pada bidangnya yang akan menjadi bagian dari ASN (Tobirin, 2018).

Rekrutmen pegawai merupakan salah satu unsur pentingdalampengadaanpegawai di lingkunganPemerintahan Daerah. Menurut (Ramandey, 2014)bahwa penerapan sistem merit berpengaruh terhadap pengadaan ASN, hal ini disebabkan karena dalam rangka menuju ASN yang professional harus menggunakan system merit dalam pengadaan ASN baik itu pengadaan CPNS maupun PPPK merupakan suatu system untuk pengelolaan system kepegawaian yang mengacu dengan kompetensi, atau kualifikasi pendidikan yang sesuai pada bidangnya. Pengadaan ASN adalah mekanisme untuk memenuhi kebutuhan dalam kepegawaian, untuk mencapai proses tersebut, maka diadakanya perekrutment pegawai dengan cara Pengadaan pegawai dimulai dari persiapan, pengumuman atau publikasi, pelamaran, tahapan Seleksi Admnistrasi, SKB, pengangkatan CPNS sampai dengan pengangkatan CPNS (aryuni, 2010). Semenjak PP tersebut berlaku maka sistem pengangkatan menjadi PNS pegawai tidak 
bisa dilakukan melalui diskresi lagi, dimana sebelumnya cukup melalui kewenangan pejabat tenaga honorer dapat bekerja dan dalam jangka waktu lama maka mereka akan diangkat langsung menjadi PNS, namun ini tidak akan terjadi lagi karena baik PNS maupun PPPK semuanya harus melalui seleksi (Juliani, 2019). Munculnya PPPK dalam dunia Kepegawaian di Indonesia bertujuan untuk mengatasi permasalahan penataan system manjemen ASN yang selama ini tidak ada kepastian hukum terutama tenaga honorer, dan diharapkan dengan PPPK ini akan menghasilkan tenaga professional, transparan, mempunyai kemampuan dan keahlian yang telah dimiliki oleh mereka dengan membuat kepastian hukum untuk setara dengan PNS (qomarani, 2020).

Sistem Pengadaan ASN secara global sama dilakukan oleh pemerintah pusat ataupun daerah di seluruh Indonesia karena sudah diatur oleh petunjuk teknis Kepala BKN baik itu Pengadaan CPNS maupun PPPK. Perbedaan pengadaan ASN terdapat pada teknis atau adanya muatan lokal yang diatur oleh SKPD masing-masing, salah satunya di lingkungan Pemkab bandung memuat pada pengadaan CPNS terdapat syarat minimal IPK dan pengadaan PPPK terdapat syarat bahwa peserta PPPK harus membuat SPTJM yang aktif mengajar sampai saat ini.Berdasarkan Perka BKN
No.1 Tahun 2019 tentang Petunjuk Teknis Pengadaan PPPK bahwa mengharuskan mereka untuk mengikuti tahapan pengadaan PPPK yang meliputi perencanaan/persiapan, pengumuman/publikasi, pelamaran, seleksi administarsi, SKB, serta hasil SKB, pengangkatan menjadi calon PPPK, dan pengangkatan menjadi PPPK. Berdasarkan ulasan yang telah diungkapkan, bahwa pengadaan PPPK tersebut banyak menimbulkan permasalahan terutama dalam kebijakan yang dibuat oleh pemerintah pusat dalam mengimplementasikan pengadaan PPPK kepada pemerintah daerah pertama dimulai dari terbitnya PP No.49 Tahun 2018 yang mengatakan bahwa tenaga Non PNS dapat diangkat melalui pengadaan PPPK namun harus melalui seleksi administratif dan kompetensi, hal ini membuat tenaga Non PNS yang sudah bekerja bertahuntahun tidak dapat diangkat secara langsung seperti kebijakan yang sebelumnya, kedua mengenai kebijakan perekrutment dalam pengadaan PPPK terutama pelamar yang mengikuti seleksi pengadaan PPPK ini dari eksternal berupa umum seluruhnya bisa ikut tanpa harus ada persyaratan khusus atau internal berupa tenaga Non PNS dengan adanya persyaratan khusus karena kebijakan dari Kemenpan RB dengan BKN terkadang tidak sejalan, kemudian ketiga masih mengenai kebijakan pengadaan PPPK dalam PP tersebut bahwa Pengadaan PPPK ini 
merupakan solusi untuk pengangkatan tenaga Non PNS yang ada di pemerintah pusat maupun daerah yang selanjutnya pemerintah daerah dalam jangka waktu lima tahun harus menyelesaikan persoalan pengangkatan tenaga Non PNS ini dengan peralihan tersebut, sehingga menimbulkan permasalahan yang harus diselesaikan pemerintah daerah guna mewujudkan kebijakan tersebut. Oleh karena itu, peneliti ingin menelaah dari implementasi kebijakan pengadaan PPPK dengan lokus di pemerintah Kabupaten Bandung.

\section{TINJAUAN PUSTAKA}

\section{Implementasi Kebijakan}

Menurut (Creswell, 2007) implementasi kebijakan adalah suatu proses yang dilakukan dengan merencanakan sesuai yang disepakati oleh pemerintah yang akan di realisasikan dengan suatu tindakan yang berdampak pada tempat tersebut akan menghasilkan diteruskan atau tidak suatu kebijakan tersebut. Menurut (Anderson, 1979) implementasi kebijakan publik merupakan suatu proses kegiatan yang dilaksanakan secara administratif setelah kebijakan ditetapkan. (Grindle, 1980) pandangan mengenai implementasi mengatakan bahwa, tugas implementasi adalah membuat suatu kaitan (linkage) yang memperlancar tujuan-tujuan kebijakan agar digunakan sebagai dampak dari suatu kegiatan pemerintahan.
Model Implementasi kebijakan mengenai Implementasi Kebijakan Pengadaan PPPK Di Lingkungan Pemkab Bandung, peneliti menggunakan teori (R.Vining, 2010)yang menyatakan bahwa : "ada tiga kelompok variabel besar yang dapat mempengaruhi keberhasilan implementasi program, yakni : (1) logika kebijakan merupakan penilaian yang dilihat dari sudut pandang tujuan dan isi kebiajakan, (2) lingkungan tempat kebijakan dioperasikan merupakan faktor internal dan eksternal yang memperngaruhi kebiajakan yang dibuat, (3) kemampuan implementor kebijakan merupakan SOP, dan kemampuan SDM, serta Koordinasi dan Komunikasi”.

Berdasarkan kutipan diatas, bahwa peneliti menggunakan model tersebut dikarenakan dalam permasalahan penelitian mencakup tiga indikator yang menjelaskan beberapa 3 indikator tersebut.

\section{METODE PENELITIAN}

Penelitian yang diteliti menggunakan metode kualitatif. Hasil yang dikumpulkan berupa data primer dan sekunder. Teknik untuk pengumpulan data tersebut menggunakan wawancara, observasi, serta dokumentasi, Validasi data digunakan teknik triangulasi (Moleong, 2010). Dalam proses wawancara, informan yang diwawancara, diantaranya :

1) Kabid Formasi dan Informasi Aparatur 
2) Kasubbid Formasi Aparatur

3) Kasubbid Pengadaan Aparatur

4) Kasubbid Data dan Informasi Aparatur

5) Kasubag Umum dan Kepegawaian terkait dalam Pengadaan PPPK

Observasi yang dilakukan adalah peneliti melakukan pengumpulan data dengan pengamatan secara langsung pada lokasi objek yang diteliti yakni lokasi observasi dalam hal ini ialah BKPSDM serta SKPD di lingkungan Pemkab Bandung untuk melihat dan mengetahui data yang dilakukan secara SOP tentang bagaimana Implementasi Kebijakan Pengadaan PPPK Di Lingkungan Pemerintah Kabupaten Bandung. Dokumentasi yang dilakukan meliputi peneliti memperoleh data-data dari data sekunder yang bisa berupa dokumen publik ataupun dokumen privat, gunanya untuk memperkuat data penelitian peneliti dalam menulis tesis dan sebagai data pendukung yang dilampirkan di halaman belakang tesis.

\section{HASIL DAN PEMBAHASAN}

Kebijakan Pengadaan Pegawai di Lingkungan Pemerintah Kabupaten

\section{Bandung}

Kebijakan pengadaan pegawai terdapat dua jenis berdasarkan UU No 5 Tahun 2014 tentang ASN yaitu pengadaan CPNS dan Pengadaan PPPK yang masingmasing diatur oleh Perka BKN No. 14 Tahun 2018 tentang Petunjuk Teknis
Pengadaan Pegawai Negeri Sipil, sedangkan pengadaan PPPK diatur dalam PP No 49 Tahun 2018 tentang Manjemen PPPK dan Perka BKN No 1 Tahun 2019 Tentang Petunjuk Teknis Pengadaan PPPK.

Mekanisme pengadaan pegawai CPNS maupun PPPK hampir sama dengan persyaratannya, hanya yang membedakannya khusus untuk pengadaan PPPK tidak melalui SKD akan tetapi langsung mengikuti SKB. Hal tersebut sudah diatur sesuai aturan yang berlaku pengadaan CPNS itu harus melalui seleksi administrasi, SKD, SKB, dan terakhir pemberkasan, sedangakan pengadaan PPPK melalui tiga tahapan yaitu seleksi administrasi, SKD, SKB, dan pemberkasan. Persyaratan untuk mengikuti pengadaan CPNS maupun PPPK sama yaitu :

1. WNI atau asli orang Indonesia;

2. Minimal Usia 18 Tahun;

3. Tidak pernah dihukum, dipenjara dengan membuktikan adanya SKCK;

4. Tidak pernah diberhentikan secara tidak hormat selama bekerja;

5. Tidak berstatus CPNS;

6. Mempunyai kualifikasi pendidikan yang sesuai dengan persyaratan;

7. Berkelakuan baik;

8. Sehat jasmani dan rohani;

9. Bersediaditempatkan dimana saja;

10. Syarat lain diatur kembali sesuai instansi 
daerah.

\section{Pegawai Pemerintah dengan Perjanjian}

Kerja

Komposisi Kepegawaian di

lingkungan Pemkab Bandung terdiri atas

PNS dan Pegawai Non PNS, dalam realitanya pegawai yang bekerja di lingkungan Pemkab Bandung ini yang statusnya PNS itu berdasarkan data BKPSDM kabupaten Bandung Tahun 2018 bahwa PNS berjumlah 16.180 dan Non PNS berjumlah 12.974 sehingga total keseluruhannya 29.154 pegawai yang tersebar di seluruh SKPD di lingkungan Pemkab Bandung. Pegawai Non PNS yang ada di lingkungan Pemkab bandung hampir mencapai 44,5 \% dari jumlah keseluruhan pegawai.

PPPK merupakan WNI yang telah mengikuti seleksi berstatus lulus yang diangkat menjadi calon PPPK untuk membantu menjalankan pemerintahan. Pengadaan PPPK adalah suatu kegiatan yang dilakukan untuk memenuhi kebutuhan tiap-tiap SKPD dengan proses tahapan persiapan,publikasi, pelamaran, seleksi Administrasi/SKB, pengumuman hasil seleksi, dan pengangkatan PPPK.

a. Perencanaan/Persiapan

Perencanaan/Persiapan dalam pengadaan PPPK ini dimulai dari usulan formasi yang diusulkan pemerintah daerah ke Kemenpan RB, kemudian dari Kemenpan
RB akan menjawab atau membalas usulan tersebut dengan jumlah yang ditetapkan oleh Kemenpan RB. Pembentukan Panitia daerah atau disebut Panselda yang didalamnya bertugas untuk mengawasi dan mengatur jalannya kegiatan pengadaan PPPK bekerjasama dengan instansi vertikal yang ada di lingkungan pemerintah.

b. Pengumuman/publikasi

Pegumuman lowongan dilakukan melalui media elektronik maupun media cetak, ini wajib dilakukan oleh pemerintah pusat maupun daerah untuk menginformasikan kepada seluruh masyarakat di Indonesia mengenai peneriamaan PPPK.

c. Pelamaran

Pelamaran ini hal yang dilakukan Panselda melakukan tugasnya dengan menerima pelamar sesuai dengan persyaratan, dan hal ini biasa diatur kembali sesuai instansi daerah yang dilamarnya.

d. SKB

SKB dalam hal ini seleksi pengumuman ini dilakukan ketika Panselda sudah melakukan proses seleksi admnistrasi dan seleksi kompetensi bidang yang menggunakan CAT BKN.

e. Pengangkatan PPPK

Pengangkatan PPPK merupakan tahapan terakhir yang didalamnya memuat pemberkasan peserta tes yang mengikuti seleksi penerimaan PPPK, yang 
kemudian akan diusulakan Nomor Induk Pegawai (NIP) ke BKN pusat, kemudian BKN akan menetapkan NIP peserta tersebut.

\section{Implementasi Kebijakan dalam} Pengadaan PPPK

\section{Logika Kebijakan}

Permasalahan mendasar dari Kebijakan Pengadaan PPPK menjelaskan bahwa kebijakan ini dibuat bertujuan untuk melakukan peralihan status tenaga non PNS menjadi PPPK dengan melalui proses pengadaan PPPK yang mengharuskan mereka mengikuti seleksi dalam jangka waktu lima tahun kedepan untuk melakukan peralihan tersebut.Penelitian mengenai implementasi kebijakan dalam pengadaan PPPK di lingkungan pemerintah kabupaten bandung ini. Tujuan kebijakan dari Kebijakan Pengadaan PPPK untuk menyelesaikan permasalahan pengangkatan Tenaga Non PNS yang ada melalui proses pengadaan PPPK guna memenuhi kebutuhan pegawai pemerintah daerah dan dapat menyelesaikan permasalahan mengenai pengangkatan tenaga Non PNS atau tenaga honorer yang ada di lingkungan pemerintah daerah. Isi (content) dari kebijakan Pengadaan PPPK yaitu mengenai proses pengadaan PPPK yang terdiri atas perencanaan/persiapan,

pengumuman/publikasi, pelamaran, seleksi
administrasi/SKB,pengumuman hasil seleksi, pengangkatan menjadi calon PPPK, dan pengangkatan menjadi PPPK

Berdasarkan data kebutuhan formasi pegawai PPPK yang bersumber dari BKPSDM Kabupaten Bandung tahun 2019 sebagai berikut

Tabel. 1 Data Kebutuhan Formasi Pegawai PPPK Tahap 1 Tahun 2019

\begin{tabular}{|l|l|c|}
\hline NO & \multicolumn{1}{|c|}{ JABATAN } & JUMLAH \\
\hline 1. & Tenaga Guru & 348 \\
\hline 2. & Tenaga Kesehatan & 50 \\
\hline 3. & $\begin{array}{l}\text { Tenaga Penyuluh } \\
\text { Pertanian }\end{array}$ & 22 \\
\hline \multicolumn{2}{|l|}{ Total } & $\mathbf{4 2 0}$ orang \\
\hline
\end{tabular}

Sumber : BKPSDM, Tahun 2019

Berdasarkan tabel diatas bahwa formasi yang dibutuhkan dengan telah ditetapkan oleh Kemenpan RB dengan jumlah Non PNS yang ada di lingkungan Pemkab Bandung tidak sebanding, jika dilihat dari parameter ini untuk lima tahun kedepan, jikalau setiap pengadaan PPPK ini hanya menerima tiap tahunnya 420 orang dan lima tahun kedepan hanya bisa mengakomodir 2.100 orang untuk menjadi PPPK.

\section{Lingkungan tempat kebijakan}

Lingkungan Internal dan Eksternal dari kebijakan pengadaan PPPK yaitu dilihat dari peserta yang mengikuti seleksi pengadaan PPPK tersebut berasal dari 
internal organisasi yaitu dari pelamar khusus atau tenaga Non PNS itu sendiri atau eksternal organisasi yaitu dari pelamar luar atau umum. Faktor pendukung dan penghambat dari kebijkan pengadaan PPPK yaitu dilihat dari implementasi atau realisasi kebijakan pengadaan PPPK yang sudah terlaksana pada tahun 2019 yang menjadi pendukung dan yang menjadi kendala pelaksanaan tersebut. Implementasi kebijakan dalam pengadaan PPPK ini terdapat kendala dalam pelaksanaan pengadaan PPPK pada tahun 2019 sebagai berikut :

\section{Proses mekanisme pengadaan PPPK}

Proses mekanisme pengadaan PPPK mulai dari persyaratan yang diperbolehkan ikut pengadaan PPPK ini antara aturan tertinggi sampai dengan kebawahnya tidak sejalan, hal ini dibuktikan dengan kebijakan yang dalam PP yang membicarakan tentang Manjemen PPPK bahwa peserta yang ikut penerimaan seleksi PPPK itu dari umum diperuntukan untuk seluruh warga negara Indonesia sedangkan dalam surat edaran dari Kemenpan RB Nomor

B/163/FP3K/M.SM.01.00/2019 tanggal

4 Februari 2019 perihal Pengadaan PPPK Tahap I Tahun 2019 yang menyatakan dan mengistruksikan bahwa Penerimaan PPPK Tahap I harus dari tenaga Honorer atau tenaga Non
PNS, bukan hanya itu saja antar instansi yang terkait yaitu BKN dan Kemenpan RB tidak sejalan hal ini dibuktikan ketika BKN memuat Peraturan Kepala BKN No.1 Tahun 2019 tentang Petunjuk Teknis Pengadaan PPPK yangmenyatakan bahwa peserta yang ikut dalam seleksi penerimaan PPPK dari umum bukan khusus seperti surat edaran Kemenpan RB.

\section{Penetapan NIP}

Penetapan NIP juga terdapat kendala, pemerintah daerah yang sudah melaksanakan pengadaan PPPK tahun 2019 tidak kunjung selesai sampai tuntas, hal ini berbeda dengan pengadaan CPNS yang sudah diatur semuanya termasuk gaji, tunjangan dan jabatan yang akan diisi oleh PNS, sedangkan pengadaan PPPK ini gaji dan tunjangan belum ada aturan rincinya walaupun yang terbaru Peratran Presiden sudah keluar, namun didalam aturan tersebut masih menunggu peraturan kementerian dalam negeri, bebrda dengan CPNS yang sudah diatur sehingga hal ini mebuat pemerintah daerah bingung kepada kebijakan pemerintah pusat yang terkesan buru-buru namun teknis pelaksnaaannya belum sampai tuntas diaturnya sehingga sampai saat ini peserta yang sudah lulus seleksi penerimaan PPPK statusnya menjadi 
tidak jelas.

\section{Anggaran}

Anggaran salah satu termasuk faktor kendala dalam pelaksanaan PPPK, hal ini dibuktikan ketika pemerintah kabupaten bandung menyelenggarakan pelaksanan pengadaan PPPK Tahap I yang bertempat di dua lokasi yaitu SMA 1 Banjaran dan SMA 1 Rancaekek Kabupaten Bandung. Anggaran yang telah disusun di tahun 2018 yang ditetapkan ditahun awal tahun 2019, mengalami perubahan disaat itu sehingga kurang efektif, karena pemerintah kabupaten bandung dalam anggaran belum merencanakan pengadaan PPPK dan hanya ada perencanaan Pengadaan CPNS dan ini terjadi diseluruh pemerintah kabupaten.kota lainya, sehingga hal ini juga yang menyulitkan pemerintah daerah untuk mengadakan PPPK secara serentak dan mendadak, dikarenakan anggran sifatnya tidak bisa mendadak harus melalui proses yang panjang untuk ditetapkan kembali. Pelaksanaan PPPK yang dilakukan ditahun 2019 tersebut bekerjasama dengan kementrian pendidikan, sehingga pemerintah kabupaten bandung saat itu bisa menggunakan sarana dan prasarana sekolah yang menunjang CAT UNBK sehingga dari segi pembiayaan tidak tinggi seperti pengadaan CPNS.

\section{Kemampuan Implementor Kebijakan}

Kemampuan implementor kebijakan, dalam penelitian mengenai kebijakan pengadaan PPPK terdapat 3 (tiga) rincian yang termuat didalamnya meliputi :

a. Standar Operasional Prosedur (SOP) SOP dalam pnelitian ini dimaksudkan untuk mengetahui alur pelaksanaan PPPK ini sesuai dengan aturan yang berlaku

b. Sumber Daya Manusia, dalam penelitian ini mengenai kebijakan pengadaan PPPK, Sumber Daya Manusia yang dimaksud pegawai yang terkait didalam pelaksana pengadaan PPPK atau sebagai panitia yang terlibat langsung dalam pelaksanaanya

c. Komunikasi dan Koordinasi dalam penelitian ini, dilihat dari stakeholder atau si implementornya yaitu BKPSDM Kabupaten Bandung dalam menyampaikan komunikasi atau koordinasi sebagai pemerintah daerah dalam mengimplementasikan kebijakan pusat tersebut.

Kemampuan Implementor Kebijakan dalam pengadaan PPPK di lingkungan pemerintah Kabupaten Bandung dalam hal ini yaitu BKPSDM Kabupaten Bandung, yang tugas dan fungsinya dibawah bidang 
Formasi dan Informasi Aparatur yang terdiri atas :

\section{Visi Misi}

Salah satu perangkat daerah pemerintah Kabupaten Bandung yaitu BKPSDM Kabupaten Bandung menetapkan visinya sebagai berikut

\section{: “Mewujudkan Kualitas Aparatur} Sipil Negara Yang Berdaya Saing, Berintegritas, Dan Melayani”.

Selanjutnya untuk mencapai keberhasilan visi tersebut, maka ditetapkan BKPSDM Kabupaten

Bandung sebagai berikut :

1. Memantapkan Pembinaan Dan Pengembangan ASN

2. Memantapkan penilaian benefit Pelayanan Administrasi

Kepegawaian yang Berbasis TI

3. Memantapkan Pembinaan Dan Pengembangan ASN melalui penilaian penilaian prestasi kerja

4. Memantapkan tatakelola instansi

BKPSDM

BandungImplementasi Kapupaten dalam pengadaan Kebijakan lingkungan pemerintah Kabupaten Bandung termasuk pada poin pertama dalam misi yang ada di BKPSDM Kabupten Bandung yaitu memantapkan Pembinaan dan pengembangan ASN salah satunya melalui pengadan ASN atau pengadaan pegawai.
2. Tugas dan fungsi pokok

BKPSDM mempunyai tupoksi melaksanakan program kegiatan kebijakan daerah yang mencakup bidang pelayanan ASN, perpindahan/mutasi, pengembangan kompetensi/pegawai, diklat serta melakukan fungsi Badan. Sedangkan Fungsi BKPSDM adalah :

- Perumusan dalam kebijakan teknis sesuai pada tugasnya;

- Mendukung atas penyelenggaraan pemda sesuai dengan pada tugasnya;

- pembinaan dan pelaksanaan tugas;

- pelaksanaan tugas lain yang diberikan oleh Bupati sesuai aturan.

Salah satu bidang yang membawahi kebijakan pengadaan PPPK adalah Bidang Formasi dan Informasi Aparatur. Implementasi kebijakan tersebut di jalani oleh sub bidang Pengadaan ASN. Berdasarkan uraian diatas bahwa pengadaan PPPK termasuk dalam bidang formasi dan informasi aparatur dengan sub bidang dibawahnya adalah pengadaan aparatur. Pengadaan Aparatur ini sendiri bertanggung jawab untuk menyelenggarakan pengadaan PPPK maupun CPNS atau disebut ASN, makaimplementornya adalah BKPSDM Kabupaten Bandung sesuai dengan tupoksinya. 


\section{KESIMPULAN}

Implementasi Kebijakan Pengadaan PPPK di Lingkungan Kabupaten Bandung telah dilakukan dengan melalui prosesproses sebagai berikut:

1. Logika kebijakan

Kebijakan Pengadaan PPPK ini dibuat bertujuan untuk melakukan peralihan status tenaga non PNS menjadi PPPK dengan melalui proses pengadaan PPPK yang mengharuskan mereka mengikuti seleksi dalam jangka waktu lima tahun kedepan untuk melakukan peralihan tersebut. Berdasarkan data yang dicatat melalui BKPSDM Kabupaten Bandung antara formasi yang disiapkan tidak sebanding dengan jumlah tenaga honorer/tenaga non PNS yang jauh lebih besar jumlah, sehingga ini dapat disimpulkan bahwa kebijakan ini tidak dapat menjadi solusi untuk peralihan status tenaga Non PNS menjadi ASN.

2. Lingkungan kebijakan dioperasikan Lingkungan kebijakan pengadaan PPPK yang dilakukan di lingkungan pemerintah kabupaten Bandung mempunyai kendala salah satunya adalah anggaran yang tidak bisa fleksibel untuk mengimplementasikan kebijakan tersebut secara mendadak, sehingga membuat pemda kesulitan untuk mengimplementasikan kebijakan ini.
3. Kemampuan implementor kebijakan dipengaruhi 3(tiga) faktor yaitu SOP, SDM, Koordinasi dan Komunikasi.

a. Standar Operasional Prosedur (SOP) merupakan bagian sangat penting dalam suatu pemegang kebijakan atau pelaksana kebijakan yang disebut implementor sebagai acuan dalam melaksanakan kebijakan.

b. SDM

merupakan suatu bagian yang tidak terlepas dari pelaksanaan/implementasi kebijakan pengadaan PPPK sebagai pengatur atau pengawas dalam menjalankan kebijakan pengadaan PPPK.

c. Koordinasi dan Komunikasi merupakan bagian terpenting dalam lancarnya pelaksanaaan kebijakan pengadaan PPPK sebagai media perantara baik dari implementornya atau sasaran yang dituju dalam kebijakan pengadaan PPPK ini.

Berdasarkan hasil dan pembahasan diatas dapat disimpulkan bahwa implementasi kebijakan dalam pengadaan PPPK di lingkungan pemkab Bandung masih terdapat kendala yang ditemukan dalam pelaksanaan yaitu proses mekanisme pengadaan, penetapan NIP, dan anggaran. Implementasi kebijakan mengenai PPPK yang diatur dalam PP No.49 Tahun 2018 bahwa pegawai Non PNS di lingkungan 
pemerintah daerah harus beralih menjadi PNS atau PPPK tidak akan tercapai disebabkan kebutuhan formasi dengan jumlah pegawai non PNS yang ada tidak sebanding sehingga kebijakan ini tidak dapat dilakukan di pemkab Bandung. Guna mengatasi permasalahan ini sebaiknya pemkab Bandung melakukan koordinasi dan konsultasi intensif terkait jumlah tenaga honorer yang ada di lingkungan pemkabBandung dan jangka waktu untuk mewujudkan implementasi tersebut.

\section{DAFTAR PUSTAKA}

Anderson, J. (1979). Public Policy Making (Second ed). New York: Holt Renehart and Winston.

Aryuni, w. (2010). Peranan Badan Kepegawaian Daerah Dalam Pelaksanaan Rekrutmen Pegawai Negeri Sipil (Studi Pada Badan Kepegawaian Daerah Kota Pematangsiantar).

Ayunintyas, N. (2017). (PDF) Perlindungan Hukum Pegawai Pemerintah Dengan Perjanjian Kerja Untuk Mewujudkan Reformasi Birokrasi .

Bandung, B. K. (n.d.). Retrieved Juni 17, 2020, https://bkpsdm.bandungkab.go.id/.

Creswell, J. (2007). Qualitative Inquiry \& Research Design (2nd edition ed.). California: Sage Publications.

Faedlulloh, d. (2015). Kerja Dalam Kesetaraan: Studi Pegawai Pemerintah dengan Perjanjian Kerja (PPPK) dalam Proyeksi Konfigurasi Aparatur Sipil Negara (Asn) Di Indonesia. dodi faedululloh.

Grindle, M. S. (1980). Politics and Policy Implementation in the Third World. Princeton University Press.
Juliani,

$\mathrm{H}$.

(2019).

DiskresiDalamRekrutmenPegawai

Non Pegawai Negeri Sipil Setelah Pemberlakuan Peraturan Pemerintah Nomor 49 Tahun 2018 tentang Manajemen Pegawai Pemerintah Dengan Perjanjian Kerja.

Kurniawan, R. (2020). Upaya Pemerintah dalam Menerapkan Peraturan Pemerintah No.49 Tahun 2018 Tentang Pegawai Pemerintah Dengan Perjanjian Kerja (P3K) dI Kabupaten Aceh Utara.

Moleong, L. (2010). Metodologi Penelitian Kualitatif. Bandung.

Qomarani,<smiles>[AlH2]</smiles>
Anomali_Kehadiran_Pegawai_Peme rintah_Dengan_Perjanjian_Kerja_Pp pk_Dalam_Cakrawala_Kepegawaian Di_Indonesia.

R.Vining, D. a. (2010). Policy Analysis. upper saddle river, new jersey.
Ramandey, L. (2014).
DampakPenerapanSistem Merit terhadapRekrutmenPegawai Negeri Sipil pada Badan Kepegawaian Pendidikan dan pelatihan Kota Jayapura.

Tobirin.

Tantangan_dan_Peluang_Penerapan _Manajemen_Berbasis_Kinerja_Pad a_Pegawai_Pemerintah_Dengan_Per janjian_Kerja_di_Daerah. 